11. Treon SP, Castillo JJ, Skarbnik AP, et al. The BTK inhibitor ibrutinib may protect against pulmonary injury in COVID-19-infected patients. Blood 2020;135:1912-5.

12. Florence JM, Krupa A, Booshehri LM, Davis SA, Matthay MA, Kurdowska AK. Inhibiting Bruton's tyrosine kinase rescues mice from lethal influenza-induced acute lung injury. Am J Physiol Lung Cell Mol Physiol 2018;315:L52-8.

13. Krupa A, Fudala R, Florence JM, et al. Bruton's tyrosine kinase mediates Fc $\gamma$ RIIa/Toll-like receptor-4 receptor crosstalk in human neutrophils. Am J Respir Cell Mol Biol 2013;48:240-9.

14. Kurdowska A, Matthay MA, Krupa A, Florence J. Targeting Bruton's tyrosine kinase has a protective effect in influenza A virus induced acute lung injury. Am J Respir Crit Care Med 2015;191:A6103.

15. Woyach JA. How I manage ibrutinib-refractory chronic lymphocytic leukemia. Blood 2017;129:1270-4.

16. Hampel PJ, Ding W, Call TG, et al. Rapid disease progression following discontinuation of ibrutinib in patients with chronic lymphocytic leukemia treated in routine clinical practice. Leuk Lymphoma 2019;60:2712-9.

17. Parikh SA, Achenbach SJ, Call TG, et al. The impact of dose modification and temporary interruption of ibrutinib on outcomes of chronic lymphocytic leukemia patients in routine clinical practice. Cancer Med 2020;9:3390-9.

18. Scarfò L, Chatzikonstantinou T, Rigolin GM, et al. COVID-19 severity and mortality in patients with chronic lymphocytic leukemia: a joint study by ERIC, the European Research Initiative on CLL, and CLL Campus. Leukemia 2020;34:2354-63.

\section{Ruxolitinib-induced extreme thrombocytosis in a COVID-19 patient}

TO THE EDITOR: The SARS-CoV-2 pandemic is a global health crisis. Currently, there is still no specific treatment for coronavirus disease 2019 (COVID-19), but ruxolitinib has been used in treating COVID-19 [1, 2]. In fact, the clinical effectiveness and safety profile, which includes adverse events of ruxolitinib, is still being studied in patients with COVID-19. Ruxolitinib is a JAK-2 and JAK-1 inhibitor approved for myelofibrosis, including primary myelofibrosis, post-polycythemia vera myelofibrosis, post-essential thrombocythemia myelofibrosis, polycythemia vera, and for patients who have had an inadequate response to hydroxyurea and steroid-refractory acute graft-versus-host disease [3-6].

A 52-year-old healthy and non-obese (BMI 24.09) man started having fever $\left(39.5^{\circ} \mathrm{C}\right)$, odynophagia, asthenia, adynamia, and cough five days prior to his arrival at the emergency department. Three days later, he developed tachypnea and dyspnea with an oxygen saturation of $82 \%$ at room air, which made him require oxygen supplementation. During his initial intrahospital hours, the patient was transferred to the intensive care unit (ICU), diagnosed with severe pneumonia due to SARS-CoV-2, which was confirmed by nasal swab RT-PCR test and tomography thorax score CO-RADS category 5 , and initiated on standard therapy. Twenty-four hours later in the ICU, persistent deterioration required mechanical ventilation (MV), and lopinavir/ritonavir (LPV/r) 200/50 mg BID was started. The patient was included in a ruxolitinib (10 mg BID) clinical trial; therefore,

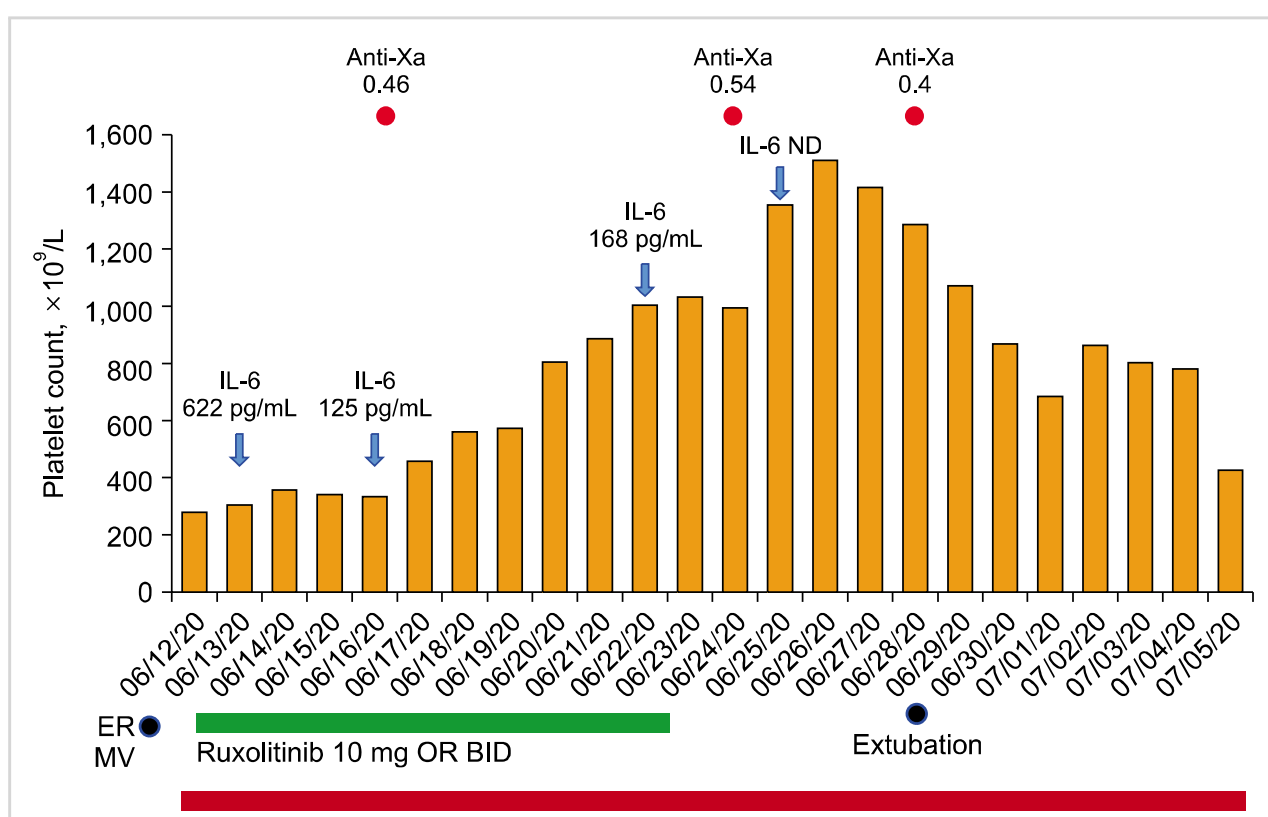

Enoxaparin $80 \mathrm{mg}$ SC BID
Fig. 1. Platelet count (yellow bars), ruxolitinib treatment period (green bar), anticoagulant and Anti-Xa levels (red colors), IL-6 levels (blue arrows).

Abbreviations: ER, emergency Room; $\mathrm{MV}$, mechanical ventilation; $\mathrm{ND}$, non-detectable; $\mathrm{OR}$, oral route; $\mathrm{SC}$, subcutaneous. 
$\mathrm{LPV} / \mathrm{r}$ was suspended due to possible interactions. During follow-up, we identified a progressive platelet count increase (Fig. 1), which was assessed at the pharmacovigilance institutional center as a suspected adverse drug reaction related to ruxolitinib, based on the temporality of the platelet count rise and the duration of the ruxolitinib effect. After stopping ruxolitinib, the platelet count decreased and normalized, and interleukin-6 levels decreased until they were undetectable on day 13 after ruxolitinib, without relevant changes in the rest of the inflammatory markers. We administered an anticoagulation treatment with enoxaparin $80 \mathrm{mg}$ SC BID, maintaining anti-Xa therapeutic levels, and the patient was discharged without clinical complications.

In controlled clinical trials, thrombocytosis has not been reported as an adverse effect in the context of myeloproliferative diseases or graft-versus-host disease. In addition, there are only isolated case reports, and it is not included as an expected adverse effect in commercial pharmaceutical information. This phenomenon is possibly due to multifactorial causes, such as reduction in phagocytic activity, reduction of splenic sequestration, incomplete JAK-2 inhibition, or activation of kinases not yet described with megakaryopoiesis dysregulation [3-7]. To our knowledge, this is the first case of ruxolitinib-induced extreme thrombocytosis in the context of COVID-19 in a patient without hematological disease, and should be considered as an extraordinarily rare side effect, which may increase the risk of fatal thromboembolic events.

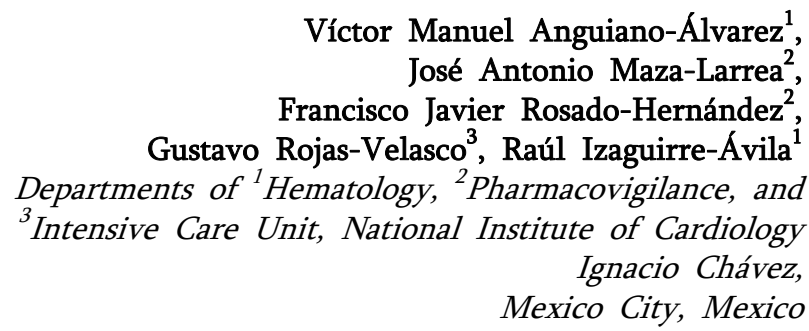

Correspondence to: Víctor Manuel Anguiano-Álvarez Department of Hematology, National Institute of Cardiology Ignacio Chávez, Calle Juan Badiano 1, Col. Sección XVI, Tlalpan, 14080 Ciudad de México, Mexico E-mail:vanguiano@comunidad.unam.mx

Received on Sep. 29, 2020; Revised on Mar. 2, 2021; Accepted on Jul. 8, 2021 https://doi.org/10.5045/br.2021.2020245

\section{Authors' Disclosures of Potential Conflicts of Interest}

No potential conflicts of interest relevant to this article were reported.

\section{REFERENCES}

1. Cao Y, Wei J, Zou L, et al. Ruxolitinib in treatment of severe coronavirus disease 2019 (COVID-19): a multicenter, single-blind, randomized controlled trial. J Allergy Clin Immunol 2020; 146:137-46, e3.
2. Giudice V, Pagliano P, Vatrella A, et al. Combination of ruxolitinib and eculizumab for treatment of severe SARS-CoV-2-related acute respiratory distress syndrome: a controlled study. Front Pharmacol 2020;11:857.

3. Vannucchi AM, Kiladjian JJ, Griesshammer M, et al. Ruxolitinib versus standard therapy for the treatment of polycythemia vera. N Engl J Med 2015;372:426-35.

4. Verstovsek S, Mesa RA, Gotlib J, et al. A double-blind, placebo-controlled trial of ruxolitinib for myelofibrosis. N Engl J Med 2012;366:799-807.

5. Harrison C, Kiladjian JJ, Al-Ali HK, et al. JAK inhibition with ruxolitinib versus best available therapy for myelofibrosis. N Engl J Med 2012;366:787-98.

6. Zeiser R, von Bubnoff N, Butler J, et al. Ruxolitinib for glucocorticoid-refractory acute graft-versus-host disease. N Engl J Med 2020;382:1800-10.

7. Polverelli N, Catani L, Vianelli N, Baccarani M, Cavo M, Palandri F. Ruxolitinib- but not fedratinib-induced extreme thrombocytosis: the combination therapy with hydroxyurea and ruxolitinib is effective in reducing platelet count and splenomegaly/constitutional symptoms. Ann Hematol 2015;94:1585-7.

\section{Romiplostim plus danazol as salvage treatment for eltrombopag refractory immune thrombocytopenia: a retrospective pilot study}

TO THE EDITOR: The thrombopoietin (TPO) pathway is the primary signaling mechanism that drives platelet production [1]. In healthy individuals, the TPO pathway is activated in response to circulating platelet levels. However, patients with immune thrombocytopenic purpura (ITP) cannot mount an adequate TPO-mediated response to compensate for the immune-mediated platelet destruction, leading to a net decrease in platelet count [2-5]. TPO receptor agonists (TPO-RA) bind and activate the TPO receptor in ITP patients. ITP is effectively treated with TPO-RAs, namely eltrombopag and romiplostim. However, some patients do not benefit from the initially prescribed TPO-RA $[6,7]$. Since the pharmacodynamic and pharmacokinetic properties of eltrombopag and romiplostim differ from one another, switching to an alternate TPO-RA is a viable salvage treatment option. Retrospective clinical data reported response rates ranging from $65 \%$ to $100 \%$ after switching from eltrombopag to romiplostim [8-12]. In this report, we share our experience of switching TPO-RAs in heavily treated ITP patients. The efficacy of romiplostim was maximized by adding danazol.

This was a retrospective pilot study involving adult patients over 18 years old, diagnosed with chronic ITP but failed to respond to corticosteroids, intravenous immunoglobulin, and eltrombopag. The diagnosis and response eval- 